\title{
Adherence to the Mediterranean Lifestyle and Desired Body Weight Loss in a Mediterranean Adult Population with Overweight: A PREDIMED-Plus Study
}

\author{
Cristina Bouzas ${ }^{1,2,3} \mathbb{D}^{-}$, Maria del Mar Bibiloni ${ }^{1,2,3}$, Alicia Julibert ${ }^{1,2,3}$, Miguel Ruiz-Canela ${ }^{1,4}(\mathbb{D}$, \\ Jordi Salas-Salvadó ${ }^{1,5,6}{ }^{\mathbb{D}}$, Dolores Corella ${ }^{1,7} \mathbb{D}$, Maria Dolors Zomeño ${ }^{1,8,9}$,

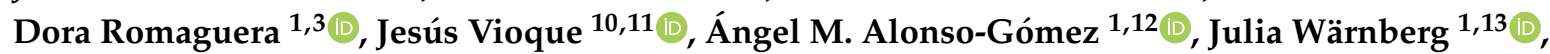 \\ J. Alfredo Martínez 1,14,15 , Luís Serra-Majem 1,16 ${ }^{\mathbb{D}}$, Ramon Estruch 1,17 (D), \\ Francisco J. Tinahones ${ }^{1,18}$, José Lapetra ${ }^{1,19}$, Xavier Pintó ${ }^{1,20}$, Antonio García Ríos ${ }^{1,21}$, \\ Aurora Bueno-Cavanillas 11,22 (D), José J. Gaforio 11,23 (D), Pilar Matía-Martín 24, Lidia Daimiel ${ }^{25}$ (D), \\ Vicente Martín-Sánchez ${ }^{26,27}$ (D) Josep Vidal ${ }^{28}$, Clotilde Vázquez ${ }^{1,29}$, Emilio Ros ${ }^{1,30}$ (D), \\ Cesar Ignacio Fernandez-Lázaro ${ }^{1,4} \mathbb{D}$, Nerea Becerra-Tomás ${ }^{1,5}$, \\ Ignacio Manuel Gimenez-Alba 1,7 (D), Julia Muñoz 1,8, Marga Morey 1,3, \\ Alejandro Oncina-Canovas 10,11, Lucas Tojal-Sierra 2,12, Jéssica Pérez-López 1,13 (iD, \\ Itziar Abete 1,15 (D), Tamara Casañas-Quintana 1,16, Sara Castro-Barquero 1,17, \\ M. Rosa Bernal-López 1,18 (D), José Manuel Santos-Lozano 1,19, Ana Galera ${ }^{1,20}$, \\ Escarlata Angullo-Martinez 1,2,3,31, F. Javier Basterra-Gortari 1,4,32, Josep Basora 1,5, \\ Carmen Saiz ${ }^{1,7}$, Olga Castañer 1,8 (D), Marian Martín 1,3, Leyre Notario-Barandiarán 10,11, \\ María C. Belló-Mora 1,12, Carmen Sayón-Orea 1,4,32, Jesús García-Gavilán 1,5, Albert Goday 1,8 \\ and Josep A. Tur 1,2,3,*(D)
}

1 CIBER Fisiopatología de la Obesidad y Nutrición (CIBEROBN), Instituto de Salud Carlos III (ISCIII), 28029 Madrid, Spain; cristinabouvel@gmail.com (C.B.); mar.bibiloni@uib.es (M.d.M.B.); alicia.julibert@uib.es (A.J.); mcanela@unav.es (M.R.-C.); jordi.salas@urv.cat (J.S.-S.); dolores.corella@uv.es (D.C.); mzomeno@imim.es (M.D.Z.); mariaadoracion.romaguera@ssib.es (D.R.); angelmago13@gmail.com (Á.M.A.-G.); jwarnberg@uma.es (J.W.); jalfredo.martinez@imdea.org (J.A.M.); lluis.serra@ulpgc.es (L.S.-M.); restruch@clinic.cat (R.E.); fjtinahones@hotmail.com (F.J.T.); joselapetra543@gmail.com (J.L.); xpinto@bellvitgehospital.cat (X.P.); angarios2004@yahoo.es (A.G.R.); cvazquezma@gmail.com (C.V.); eros@clinic.cat (E.R.); cflazaro@unav.es (C.I.F.-L.); nerea.becerra@urv.cat (N.B.-T.); i.gimenez.alba@valencia.edu (I.M.G.-A.); juliamm02@gmail.com (J.M.); marga.morey@yahoo.es (M.M.); jessicaperezlopez@uma.es (J.P.-L.); iabetego@unav.es (I.A.); tamara.nutricion@gmail.com (T.C.-Q.); scastro@clinic.cat (S.C.-B.); robelopajiju@yahoo.es (M.R.B.-L.); josemanuel.santos.lozano@gmail.com (J.M.S.-L.); agalera@idibell.cat (A.G.); eangullo@ibsalut.caib.es (E.A.-M.); javierbasterra@hotmail.com (F.J.B.-G.); jbasora.tgn.ics@gencat.cat (J.B.); carmen.saiz@uv.es (C.S.); ocastaner@imim.es (O.C.); marian.martin@gmail.com (M.M.); marujabello@gmail.com (M.C.B.-M.); csayon@unav.es (C.S.-O.); jesusfrancisco.garcia@urv.cat (J.G.-G.); Agoday@parcdesalutmar.cat (A.G.)

2 Research Group on Community Nutrition \& Oxidative Stress, University of Balearic Islands, Guillem Colom Bldg, Campus, 07122 Palma de Mallorca, Spain; lutojal@hotmail.com

3 Health Research Institute of the Balearic Islands (IdISBa), 07120 Palma de Mallorca, Spain

4 Department of Preventive Medicine and Public Health, IdISNA, University of Navarra, 31008 Pamplona, Spain

5 Universitat Rovira i Virgili, Department of Biochemistry and Biotechnology, Human Nutrition Unit, 43201 Reus, Spain

6 Institut d'Investigació Sanitària Pere Virgili (IISPV), 43201 Reus, Spain

7 Department of Preventive Medicine, University of Valencia, 46100 Valencia, Spain

8 Unit of Cardiovascular Risk and Nutrition, Institut Hospital del Mar de Investigaciones Médicas Municipal d'Investigació Mèdica (IMIM), 08003 Barcelona, Spain

9 Blanquerna School of Health Sciences, Universitat Ramon Llull, 08022 Barcelona, Spain

10 Unit of Nutritional Epidemiology, Miguel Hernández University, ISABIAL-UMH, 46020 Alicante, Spain; vioque@umh.es (J.V.); aoncina@umh.es (A.O.-C.); lnotario@umh.es (L.N.-B.) 
11 CIBER Epidemiología y Salud Pública (CIBERESP), Instituto de Salud Carlos III (ISCIII), 28029 Madrid, Spain; abueno@ugr.es (A.B.-C.); jgaforio@ujaen.es (J.J.G.)

12 Bioaraba Health Research Institute; Osakidetza Basque Health Service, Araba University Hospital, University of the Basque Country UPV/EHU, 48013 Vitoria-Gasteiz, Spain

13 Department of Nursing, School of Health Sciences, University of Málaga-IBIMA, 29071 Málaga, Spain

14 Precision Nutrition Program, IMDEA Food, CEI UAM + CSIC, 28049 Madrid, Spain

15 Department of Nutrition, Food Sciences, and Physiology, Center for Nutrition Research, University of Navarra, 31008 Pamplona, Spain

16 Institute for Biomedical Research, University of Las Palmas de Gran Canaria, 35016 Las Palmas de Gran Canaria, Spain

17 Department of Internal Medicine, IDIBAPS, Hospital Clinic, University of Barcelona, 08036 Barcelona, Spain

18 Virgen de la Victoria Hospital, Department of Endocrinology, Biomedical Research Institute of Málaga (IBIMA), University of Málaga, 29010 Málaga, Spain

19 Department of Family Medicine, Research Unit, Distrito Sanitario Atención Primaria Sevilla, 41013 Sevilla, Spain

20 Lipids and Vascular Risk Unit, Internal Medicine, Hospital Universitario de Bellvitge, Hospitalet de Llobregat, 08907 Barcelona, Spain

21 Lipids and Atherosclerosis Unit, Department of Internal Medicine, Maimonides Biomedical Research Institute of Cordoba (IMIBIC), Reina Sofia University Hospital, University of Cordoba, 14004 Cordoba, Spain

22 Department of Preventive Medicine, University of Granada, 18071 Granada, Spain

23 Department of Health Sciences, Centro de Estudios Avanzados en Olivar y Aceites de Oliva, University of Jaen, 23071 Jaen, Spain

24 Department of Endocrinology and Nutrition, Instituto de Investigación Sanitaria Hospital Clínico San Carlos (IdISSC), 28040 Madrid, Spain; pilar.matia@gmail.com

25 Nutritional Genomics and Epigenomics Group, IMDEA Food, CEI UAM + CSIC, 28049 Madrid, Spain; lidia.daimiel@imdea.org

26 CIBER Diabetes y Enfermedades Metabólicas (CIBERDEM), Instituto de Salud Carlos III (ISCIII), 28029 Madrid, Spain; vicente.martin@unileon.es

27 Institute of Biomedicine (IBIOMED), University of León, 24071 León, Spain

28 Department of Endocrinology, IDIBAPS, Hospital Clinic, University of Barcelona, 08036 Barcelona, Spain; jovidal@clinic.cat

29 Department of Endocrinology, Fundación Jiménez-Díaz, 28040 Madrid, Spain

30 Lipid Clinic, Department of Endocrinology and Nutrition, Institut d'Investigacions Biomèdiques August Pi Sunyer (IDIBAPS), Hospital Clínic, 08036 Barcelona, Spain

31 Escola Graduada Primary Health Care Center, IBSalut, 07002 Palma de Mallorca, Spain

32 Servicio Navarro de Salud, Osasunbidea, 31071 Pamplona, Spain

* Correspondence: pep.tur@uib.es; Tel.: +34-971-1731; Fax: +34-971-173184

Received: 2 June 2020; Accepted: 9 July 2020; Published: 16 July 2020

Abstract: Background. Body weight dissatisfaction is a hindrance to following a healthy lifestyle and it has been associated with weight concerns. Objectives. The aim of this study was to assess the association between the adherence to the Mediterranean lifestyle (diet and exercise) and the desired body weight loss in an adult Mediterranean population with overweight. Methods. Cross-sectional analysis in 6355 participants (3268 men; 3087 women) with metabolic syndrome and BMI (Body mass index) between 27.0 and $40.0 \mathrm{~kg} / \mathrm{m}^{2}$ (55-75 years old) from the PREDIMED-Plus trial. Desired weight loss was the percentage of weight that participants wished to lose. It was categorized into four cut-offs of this percentage (Q1: $<10 \%, n=1495 ; \mathrm{Q} 2: 10-15 \%, n=1804 ; \mathrm{Q} 3:<15-20 \%$, $n=1470 ; \mathrm{Q} 4: \geq 20 \%, n=1589)$. Diet was assessed using a validated food frequency questionnaire and a 17-item Mediterranean diet questionnaire. Physical activity was assessed by the validated Minnesota-REGICOR and the validated Spanish version of the Nurses' Health Study questionnaire. Results. Participants reporting higher percentages of desired weight loss (Q3 and Q4) were younger, had higher real and perceived BMI and were more likely to have abdominal obesity. Desired weight loss correlated inversely to physical activity (Q1: 2106 MET min/week; Q4: 1585 MET min/week. 
$p<0.001)$ and adherence to Mediterranean diet (Q1: 8.7; Q4: 8.3. $p<0.001)$. Conclusions. In older Mediterranean individuals with weight excess, desired weight loss was inversely associated with Mediterranean lifestyle adherence. Deeply rooted aspects of the MedDiet remained similar across groups. Longitudinal research is advised to be able to establish causality.

Keywords: body image; mediterranean lifestyle; overweight; obesity; older adults; desired weight loss; ideal weight; PREDIMED-Plus

\section{Introduction}

Despite a recent meta-analysis describing that overweight or obesity may decrease mortality risk in elderly populations [1], this could be due to a higher resistance of the overweight people to severe physical stress, as would be the case for inpatients in intensive care units [2]. On the other hand, sarcopenic obesity increased risk for all-cause mortality [3]. Ju et al. described that other parameters closely related to obesity, such as metabolic syndrome, increase mortality. However, they do not describe in detail parameters of body composition when they refer to weight excess as a protective factor for mortality [1]. Moreover, the excess of body weight and body fat is associated with a higher risk of several diseases, which are direct causes of a decrease in quality of life and mortality [4-8]. Hence, body fat should be diminished to adequate levels, in order to avoid such outcomes. Aging comes to relevance especially since prevalence of non-communicable chronic diseases, such as those related to an excess of weight or susceptible of aggravating by weight, increases after 55 years of age [9]. Previous research established that the Mediterranean diet (MedDiet) is an adequate treatment to avoid cardiovascular harmful effects of excess weight and its comorbidities in population over 55 years old [10]. Several definitions of MedDiet are available through the literature. Reviews in this regard have found similarities and differences among definitions. Briefly, the MedDiet is a food pattern rich in fruits, vegetables, olive oil, whole grains, legumes, nuts, fish and a preference of white over read meat. Less consistent are the recommendations for fermentable dairy products and red wine in the literature [10-16]. From a holistic point of view, the MedDiet has been considered one of the key elements of the so-called Mediterranean lifestyle, which moreover adds to the diet qualities of eco-friendly and sustainability by the preference for locally produced, traditional and seasonal foods. Further from food itself, it also implies correct hydration, home-made food preparation, sociable eating with family or friends, regular outdoor physical activity, relaxation and rest $[14,15]$.

Rather than the objective weight status, weight perception and ideal weight are more likely to boost weight management actions [16], as illustrated by Higgins' regulatory focus theory regarding the relationship between motivations and pursuit of a goal [17]. Accordingly, overweight perception has been associated with spontaneous weight management, mainly by dieting and/or exercising [16]. Nowadays, checking for health advice in social media has become very popular [18]. Searches comprise a wide range, from searching symptoms online with the purpose of self-diagnosis, to self-prescribing a treatment [19]. There is an increasing tendency to self-prescribe a diet [19], however, unfortunately not all information available on internet is reliable [18]. As a consequence, body weight dissatisfaction is a risk factor for engaging in unhealthy lifestyles, and it might be a hindrance to following a healthy lifestyle [16]. Nonetheless, aging has been associated with lower weight concerns and lower overweight perception. Ignoring and not tackling the excess of fat may have a negative impact on lifestyle and general health, as mentioned above $[4,16]$. Moreover, aging has been associated with lower discrepancy between current weight and desired weight [20]. Thus, it is unclear whether aging offers a protective or harmful effect on the influence of ideal weight on healthful lifestyles. The lower concern might protect individuals from unreliable health information, while a decrease in awareness might decrease interest in maintaining a healthy lifestyle. 
Body image (defined as a person's perception of their physical self [21]) has been widely studied in the young population, but it has been scarcely reported on in the aged population [16]. Body image can be assessed as body image dissatisfaction, by comparing actual and reported desired body weight [22]. On one hand, reported weight and desired weight are shifting upward, contrary to the percentage of desired weight loss (DWL), which remained more stable through time. [23,24]. As aforementioned, evidence tackling the relationship between desired weight or DWL and dietary pattern in middle aged and aged populations without eating disorders is very limited. It would be interesting to study such associations in adults with overweight. The PREDIMED-Plus study offers a golden opportunity to evaluate relations between body image defined as DWL and Mediterranean lifestyle in adults over 55 years old. Therefore, the aim of this study was to assess the association between the adherence to Mediterranean lifestyle (understood as diet and exercise) and the desired body weight loss in an adult Mediterranean population with an excess of weight.

\section{Methods}

\subsection{Study Design}

The PREDIMED-Plus trial is an ongoing 6-year multicenter, parallel-group, randomized trial. It is currently being conducted in 23 Spanish recruiting centers (universities, hospitals and research institutes). The PREDIMED-Plus trial was designed to compare the effect of a hypocaloric traditional MedDiet combined with physical activity promotion and behavioral support on cardiovascular disease morbimortality, compared with the usual care advice, consisting exclusively of an energy-unrestricted traditional MedDiet (control group). Further details on the study protocol can be found elsewhere [25] and at http://predimedplus.com/. The trial was registered in 2014 at the International Standard Randomized Controlled Trial (ISRCT; http://www.isrctn.com/ISRCTN89898870) with number 89898870 . This present research is a cross-sectional analysis of baseline data within the frame of the PREDIMED-Plus trial. Because the present research is a cross-sectional analysis of baseline data, no differences were made in the analysis by treatment group allocation.

\subsection{Participants, Recruitment and Ethics}

A total of 9677 people were contacted, of which 6874 participants were eligible for the study, and were included in the trial (Figure 1). Eligible participants were community-dwelling adults (men aged 55-75, women aged 60-75), who were overweight or obese (body mass index (BMI) between 27.0 and $40.0 \mathrm{~kg} / \mathrm{m}^{2}$ ) and meeting at least three criteria for metabolic syndrome according to the updated harmonized definition of the International Diabetes Federation, the American Heart Association and the National Heart, Lung and Blood Institute [26]. All participants provided written informed consent, and the study protocol and procedures were approved according to the ethical standards of the Declaration of Helsinki by all the participating institutions.

\subsection{Dietary Assessment}

Registered dietitians assessed baseline dietary habits through dietary intake obtained with a semi quantitative 143-item food frequency questionnaire (FFQ) [27] which has been previously validated in the Spanish population [27-29]. For each item, a regular portion size was established, and consumption frequencies were registered in 9 categories, ranging from "never or almost never" to " $\geq 6$ times/day". Energy and nutrient intakes were calculated as frequency multiplied by nutrient composition of specified portion size for each food item, using a computer program based on available information in Spanish food composition tables [30,31]. Intake of dietary supplements declared in the FFQ was also considered when assessing the total nutrient intake. Participants reporting extreme total energy intakes ( $<500$ or $>3500 \mathrm{kcal} /$ day in women or $<800$ or $>4000 \mathrm{kcal} /$ day in men) were excluded from the analysis [32]. Because 241 participants reported extreme total energy intakes; therefore, our study sample was reduced to 6633 subjects. 


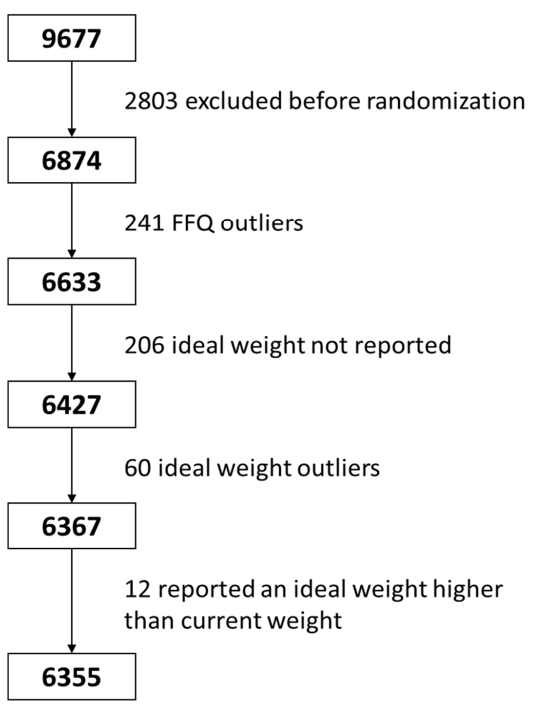

Figure 1. Flow chart of participants.

\subsection{MedDiet Adherence Assessment}

Adherence to Mediterranean dietary patterns was assessed by a modified version of the previously validated questionnaire used in the PREDIMED trial. Registered dietitians administered the 17-item MedDiet (17-item erMedDiet) questionnaire measuring adherence to an energy-restricted MedDiet [33,34] in which each item is related to a food habit (see Table 1). Compliance with food habits scored 1 for every item, otherwise scored 0 . Therefore, the 17-item MedDiet questionnaire ranged between 0 and 17 . Tertiles were made to define low, moderate or high adherence, ranging from 0 to 7,8 to 10 , and 11 to 17 , respectively, as previously published [34].

Table 1. Description of the 17-item Mediterranean dietary questionnaire.

\begin{tabular}{|c|c|c|}
\hline & Item & Compliance with the Item \\
\hline 1 & $\begin{array}{l}\text { Extra-virgin olive oil for } \\
\text { cooking }\end{array}$ & Use only extra-virgin olive oil for cooking, salad dressings, and spreads. \\
\hline 2 & Vegetables & Consume $\geq 2$ portions ( $200 \mathrm{~g}$ ) of vegetables per day, at least one of them raw. \\
\hline 3 & Fruits & Consume $\geq 3$ portions of fruit per day (including natural fruit juices). \\
\hline 4 & Red and processed meat & $\begin{array}{l}\text { Consume } \leq 1 \text { serving }(100-150 \mathrm{~g}) \text { of red meat, hamburgers, or meat products (ham, } \\
\text { sausage, etc.) per week. }\end{array}$ \\
\hline 5 & Butter, margarine, cream. & Consume less than 1 serving (12 g) of butter or cream per week. \\
\hline 6 & Sugar sweetened beverages & Consume less than one sugary beverage or sugar-sweetened fruit juice per week. \\
\hline 7 & Legumes & Consume $\geq 3$ servings ( $150 \mathrm{~g}$ ) of legumes per week. \\
\hline 8 & Fish and seafood & Consume $\geq 3$ servings of fish (100-150 g) or shellfish $(200 \mathrm{~g})$ per week. \\
\hline 9 & Sweets and pastries & $\begin{array}{l}\text { Consume }<3 \text { non-homemade sweets or pastries, such as cakes, cookies, sponge } \\
\text { cake, or custard, per week. }\end{array}$ \\
\hline 10 & Nuts & Consume $\geq 3$ servings of nuts (including peanuts) per week. \\
\hline 11 & $\begin{array}{l}\text { Preference white over red } \\
\text { meat }\end{array}$ & $\begin{array}{l}\text { Consume chicken, turkey or rabbit meat instead of beef, pork, hamburgers or } \\
\text { sausages. }\end{array}$ \\
\hline 12 & Sofrito & $\begin{array}{l}\text { Use sofrito } \geq 2 \text { times per week (Sofrito: tomato and onion sauce, with garlic and } \\
\text { aromatic herbs, simmered in olive oil.). }\end{array}$ \\
\hline 13 & Adding sugar to beverages & Replace sugar with non-caloric artificial sweeteners for beverages. \\
\hline 14 & White bread & Reduce consumption of white bread to $>1$ serving (75 g)/day. \\
\hline 15 & Whole grains & Consume whole grain cereals and whole grain pasta $\geq 5$ times per week. \\
\hline 16 & Refined cereals & Reduce consumption of non-whole grain pasta or rice $<3$ servings per week. \\
\hline 17 & Wine & $\begin{array}{l}\text { Consume } 2-3 \text { glasses ( } 200 \mathrm{~mL} / \text { glass) of wine per day (men) or } 1-2 \text { glasses of wine } \\
\text { per day (women). }\end{array}$ \\
\hline
\end{tabular}




\subsection{Desired Weight-Loss (DWL)}

An eating disorder questionnaire [25] was administered at baseline. The questionnaire aimed to detect comorbid eating disorders according to DSM-IV criteria [35]. On it perceived weight and height, as well as maximum and minimum weight, were asked. Moreover, reported ideal weight (expressed in $\mathrm{Kg}$ ) was asked to the participants in the aforementioned questionnaire. Weight and height were measured in duplicate by registered dietitians with calibrated scales (BC 418 MA Body Composition Analyzer/Scale, Tanita, Tokyo, Japan) and a wall-mounted stadiometer (Seca 213, HealthCheck Systems, Brooklyn, NY, USA), respectively. BMI was calculated as weight in kilograms divided by the square of height in meters. A total of 206 participants who did not report a subjective ideal weight were excluded from the analysis; therefore, the sample was reduced to 6427. Actual BMI was obtained with measured weight and height, while perceived BMI was calculated with reported (perceived) weight and height.

The literature has described that desired weight and reported weight are shifting upward. Nevertheless, when desired weight was examined as the percentage of body weight, such tendencies were not found $[23,24]$. Therefore a new variable was computed by subtracting subjective ideal weight from measured weight at baseline. Outliers (defined as 3 or more standard deviations (SD) from both sides of the mean) of that variable were excluded from the analysis. 60 outliers were found, therefore the sample size reduced from 6427 to 6367. If the former variable ranged between 2 and $-2 \mathrm{~kg}$, authors considered that subjective ideal and objective measured weight were similar [36,37]. Only 12 subjects reported higher desired than current weight. Since all participants were obese or overweight (BMI between 27.0 and 40.0), those twelve subjects were also excluded from the analysis. Therefore, the final sample included 6355 subjects, 3268 men and 3087 women.

The desired weight-loss at baseline (DWL) was the weight that each participant would need to lose to reach their subjective ideal weight. In the present study, DWL was expressed as a percentage (percentage of weight that they wish to lose). DWL was obtained through the following equation:

$$
\operatorname{DWL}(\% \text { desired weight loss })=\frac{(\text { baseline weight }- \text { ideal weight })}{\text { baseline weight }} \times 100
$$

Subjects were initially categorized into quartiles of the absolute value of DWL for analysis. Due to the closeness of the cutting-percentiles (p75: 20.00\%; p50: 14.65\%; p25: 10.25\%), cut-offs were made considering a $5 \%$ increase in DWL (Q1: $<10 \%$ of DWL, $n=1495$; Q2: $10-15 \%$ of DWL, $n=1804$; Q3: $<15-20 \%$ of DWL, $n=1470$; Q4: $\geq 20 \%$ of DWL, $n=1589$ ), which would make it easier to transfer results to everyday clinical practice.

\subsection{Other Variables}

Information related to smoking habits, marital status, educational level, as well as medical history and current medication were obtained. Biochemical analyses (triglycerides, total cholesterol, HDL-cholesterol and fasting plasma glucose) were performed using overnight fasting blood samples by standard enzymatic methods. Blood pressure was measured in triplicate with a validated semi-automatic oscillometer (Omron HEM, 705CP, Hoofddrop, The Netherlands) in a seated position. Waist circumference was measured in duplicate, halfway between the last rib and the iliac crest by using an anthropometric tape.

The validated Minnesota-REGICOR short physical activity questionnaire [38-40] and the validated Spanish version of the Nurses' Health Study questionnaire [41] were used to assess physical activity and sedentary behaviors, respectively.

\subsection{Statistics}

Analyses were performed with the SPSS statistical software package version 25.0 (SPSSS Inc., Chicago, IL, USA). Data are shown as mean, standard deviation (SD) and median, interquartile range (IQR). Differences among groups were tested with one-way ANOVA and Bonferroni's post-hoc analysis 
when variables followed normal distribution, or Kruskal-Wallis models in other cases. Prevalence is expressed in sample size and percentage. Difference in prevalence among groups was tested using $\chi^{2}$ (all $p$ values are two-tailed). Multivariate analysis was used to assess association between the MedDiet 17 items (dependent variables) and percentage (cut-off) of desired body weight loss (independent variables). For each item, 3 Odds Ratio (OR) were calculated: crude, adjusted by sociodemographic factors (age, BMI, physical activity, diet, education level, marital status and smoking habit), and adjusted by both sociodemographic factors and presence of metabolic syndrome components.

\section{Results}

Table 2 shows sociodemographic characteristics according to cut-offs of DWL. Participants with higher DWL (Q3 and Q4) were younger, had higher BMI (actual and perceived) and higher rates of abdominal obesity. No other components of the metabolic syndrome were different among groups except for high blood pressure and hyperglycemia in women (Supplemental Tables S1 and S2). A total of $27 \%$ of the subjects were overweight while $73 \%$ were obese. The majority of the subjects with overweight were classified into Q1 (52\%) and Q2 (35\%). On the contrary, most of the subjects with obesity were in Q4 (33\%), Q3 (28\%) and Q2 (27\%). Moreover, 68\%, 87\% and 97\% of the subjects in quartile 2, 3 and 4, respectively, had obesity. Tackling lifestyle, Q4 registered the lowest physical activity rates (Q1: $2106 \mathrm{MET}$ min/week; Q4: $1585 \mathrm{MET}$ min/week. $p<0.001)$. Although there was no difference in total energy intake according to DWL, adherence to the MedDiet decreased as DWL increased (Q1: 8.7; Q4: 8.3. $p<0.001)$. Q1 had fewer participants living alone and more married participants than the other groups. This was especially significant among women. In women, higher DWL was related to higher education levels, as well as to higher likelihood of ever smoking, but also to higher rates of abandoning tobacco consumption (Supplemental Tables S1 and S2).

MedDiet adherence evaluated with the 17-item MedDiet questionnaire is available in Table 3. Low MedDiet adherence scores were more likely to be found among participants with higher DWL (Q1: 32.6\%; Q4: 37.8\%. $p=0.007$ ), as opposed to high scores, more easily found as DWL decreased (Q1: 25.7\%; Q4: 20.6\%. $p=0.007$ ). Vegetables, fruits, nuts, red and processed meat, and sugary sweetened beverages were the most relevant items decreasing overall adherence to the MedDiet. Conversely, avoiding adding sugar to beverages was higher among Q4. Tackling genders (Supplemental Tables S3 and S4), items decreasing adherence for men were those regarding vegetables, fish and seafood and preference of white over red meat; while for women were those regarding fruits, red and processed meat, adding sugar to beverages or consumption of sugary sweetened beverages, and using olive oil for cooking.

Lastly, crude and adjusted OR for adherence to the 17 item MedDiet questionnaire items across cut-off Q1-4 of DWL are presented in Table 4. Q1 (<10\% DWL) was established as the reference. Crude and adjusted analysis shows that OR for Q3 and Q4 was 0.75-0.85 times lower than Q1 for adhering to the items regarding vegetables, fruits, red and processed meat, and sugary sweetened beverages; and 0.65-0.80 times lower for nuts. On the other hand, avoiding adding sugar to beverages in Q4 had a crude OR 1.25 times higher than the Q1, but it disappeared after adjustment. Some associations (crude OR) were found only for one gender (Supplemental Tables S5 and S6). In men, Q4 had an OR 0.75-0.80 times lower than Q1 to meet the recommendations of fish or seafood and to prefer white over red meat. In women, Q4 had an OR 1.35-1.40 times higher than Q1 to use extra virgin olive oil for cooking. 
Table 2. Sociodemographic characteristics according to percentage of desired weight loss (DWL).

\begin{tabular}{|c|c|c|c|c|c|c|c|c|c|}
\hline & \multicolumn{2}{|c|}{ Q1 $\mathrm{S}(n=1492)$} & \multicolumn{2}{|c|}{ Q2 $\S(n=1804)$} & \multicolumn{2}{|c|}{ Q3 $\$(n=1470)$} & \multicolumn{2}{|c|}{$\mathrm{Q} 4 \S(n=1589)$} & \multirow[b]{2}{*}{$P$} \\
\hline & Mean (SD) & Median (IQR) & Mean (SD) & Median (IQR) & Mean (SD) & Median (IQR) & Mean (SD) & Median (IQR) & \\
\hline Age (years) & $65.9(5.0)$ & $66.0(8.0)^{a, b, c}$ & $65.0(4.8)$ & $65.0(8.0)^{\mathrm{a}, \mathrm{e}}$ & $64.8(4.9)$ & $65.0(7.0)^{\mathrm{b}, \mathrm{f}}$ & $64.3(4.7)$ & $64.0(7.0)^{c, e, f}$ & $<0.001$ \\
\hline BMI $\left(\mathrm{kg} / \mathrm{m}^{2}\right)$ & $29.8(2.2)$ & $29.5(2.9)^{a, b, c}$ & $31.5(2.8)$ & $31.2(3.7)^{\mathrm{a}, \mathrm{d}, \mathrm{e}}$ & $33.2(2.9)$ & $33.0(4.0)^{b, d, f}$ & $35.5(2.9)$ & $35.5(4.3)^{c, e, f}$ & $<0.001$ \\
\hline Perceived BMI $\left(\mathrm{kg} / \mathrm{m}^{2}\right)$ & $30.0(2.7)$ & $29.6(3.1)^{a}, \mathrm{a}, \mathrm{c}, \mathrm{c}$ & $31.5(2.9)$ & $31.2(3.9)^{a} \mathrm{ad}, \mathrm{e}$ & $33.2(3.3)$ & $32.8(4.1)^{\mathrm{b}, \mathrm{d}, \mathrm{f}}$ & $35.4(3.3)$ & $35.4(4.6)^{c, e, f}$ & $<0.001$ \\
\hline \multicolumn{10}{|l|}{ Physical activity (PA) +} \\
\hline Total $(\mathrm{PA})+$ & $2730.8(2459.4)$ & $2106.3(2540.8)^{b}, \mathrm{c}$ & 2583.7 (2242.9) & $2055.9(2641.6)^{\mathrm{d}, \mathrm{e}}$ & $2387.7(2311.2)$ & $1762.7(2454.6)^{\mathrm{b}, \mathrm{d}, \mathrm{f}}$ & $2173.4(2194.7)$ & $1585.1(2394.4)^{c, e, f}$ & $<0.001$ \\
\hline $\begin{array}{l}\text { Light PA + } \\
\text { Lighes }\end{array}$ & $\begin{array}{l}792.8(974.7) \\
\text { (9) }\end{array}$ & $\begin{array}{r}447.6(1118.9) \\
4\end{array}$ & $\begin{array}{l}753.9(940.5) \\
\end{array}$ & 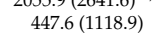 & $\begin{array}{l}761.5(949.6) \\
\text { (9) }\end{array}$ & $447.6(1118.9)$ & $\begin{array}{l}758.8(957.2) \\
(917.8)\end{array}$ & $\begin{array}{l}1000.12(1118.9) \\
447.6(11)\end{array}$ & 0.667 \\
\hline Moderate PA † & 1089.1 (1615.8) & $507.0(1573.4)^{\mathrm{b}, \mathrm{c}}$ & $1029.0(1543.8)$ & $338.0(1573.4)^{\mathrm{e}}$ & $906.2(1534.2)$ & $279.7(1398.6)^{b, f}$ & 758.7 (1374.1) & $0.0(1049.0)^{c, e, f}$ & $<0.001$ \\
\hline Intense PA + & $848.8(1633.4)$ & $86.7(1118.9)^{\mathrm{c}}$ & $800.8(1370.7)$ & $111.9(1118.9) \mathrm{d}, \mathrm{e}$ & $720.0(1384.8)$ & $83.9(925.4)^{\mathrm{d}}$ & $655.8(1277.3)$ & $55.9(839.2)^{\text {cee }}$ & $<0.001$ \\
\hline \multicolumn{10}{|l|}{ Diet } \\
\hline Energy intake (kcal/d) & $2361.1(535.8)$ & $2334.4(708.6)$ & $2368(541.7)$ & 2326 (733.4) & $2376.2(555.6)$ & $2350.3(771.2)$ & $2356.4(569.5)$ & $2318.7(780.0)$ & 0.711 \\
\hline MedDiet Q score & $8.7(2.7)^{b, c}$ & $9.0(4.0)$ & $8.5(2.7)$ & $8.0(3.0)$ & $8.4(2.6)^{\mathrm{b}}$ & $8.0(4.0)$ & $8.3(2.6)^{\mathrm{c}}$ & $8.0(4.0)$ & $<0.001$ \\
\hline Gender (female) & \multicolumn{2}{|c|}{$\begin{array}{c}n(\%) \\
662(21.4)\end{array}$} & \multicolumn{2}{|c|}{$\begin{array}{c}n(\%) \\
837(23.0)\end{array}$} & \multicolumn{2}{|c|}{$\begin{array}{c}n(\%) \\
709(23.0)\end{array}$} & \multicolumn{2}{|c|}{$\begin{array}{c}n(\%) \\
879(28.5)\end{array}$} & $<0.001$ \\
\hline BMI classification & & & & & & & & & $<0.001$ \\
\hline Overweight $(\mathrm{BMI}<30)$ & \multirow{2}{*}{\multicolumn{2}{|c|}{$\begin{array}{l}877(51.4) \\
615(13.4)\end{array}$}} & \multirow{2}{*}{\multicolumn{2}{|c|}{$\begin{array}{l}588(34.4) \\
1214(26.4)\end{array}$}} & \multirow{2}{*}{\multicolumn{2}{|c|}{$\begin{aligned} 190(11.1) \\
1267(27.6)\end{aligned}$}} & \multirow{2}{*}{\multicolumn{2}{|c|}{$\begin{array}{c}52(3.0) \\
1502(32.7)\end{array}$}} & \\
\hline Obesity (BMI > 30) & & & & & & & & & \\
\hline Education level & & & & & & & & & 0.089 \\
\hline Primary & \multicolumn{2}{|c|}{$773(52.1)$} & \multicolumn{2}{|c|}{$852(47.5)$} & \multicolumn{2}{|c|}{$684(47.1)$} & \multicolumn{2}{|c|}{$778(49.5)$} & \\
\hline Secondary & \multirow{2}{*}{\multicolumn{2}{|c|}{$\begin{array}{l}399(26.9) \\
312(21.0)\end{array}$}} & \multirow{2}{*}{\multicolumn{2}{|c|}{$\begin{array}{l}528(29.4) \\
413(23.0)\end{array}$}} & \multirow{2}{*}{\multicolumn{2}{|c|}{$\begin{array}{l}484(30.9) \\
320(22.0)\end{array}$}} & \multirow{2}{*}{\multicolumn{2}{|c|}{$\begin{array}{l}462(29.4) \\
332(21.1)\end{array}$}} & \\
\hline Tertiary & & & & & & & & & \\
\hline Smoking habit & & & & & & & & & 0.177 \\
\hline Current smoker & \multirow{2}{*}{\multicolumn{2}{|c|}{$174(11.7)$}} & & (13.4) & & (12.3) & & (12.3) & \\
\hline & & & & & & (45.2) & & & \\
\hline Never smoked & 693 & 46.7) & & (43.8) & & (42.5) & & (42.8) & \\
\hline Marital status & & & & & & & & & 0.001 \\
\hline Married & 1172 & $(79.0)$ & & (77.3) & & $(76.6)$ & & (74.1) & \\
\hline Divorced/separated & & & & (7.9) & & (7.9) & & & \\
\hline Widower & 173 & 11.7) & & (9.2) & & (10.3) & & (11.0) & \\
\hline Other \| & & & & (5.5) & & (5.2) & & & \\
\hline Living alone $\ddagger$ & 155 & 10.4) & & (13.2) & & (12.0) & & (13.3) & 0.047 \\
\hline Smoking habit & & & & & & & & & 0.177 \\
\hline Current smoker & & & & (13.4) & & (12.3) & & (12.3) & \\
\hline Former smoker & & 41.6) & & (42.8) & & $(45.2)$ & & (44.9) & \\
\hline Never smoked & & & & (43.8) & & (42.5) & & (42.8) & \\
\hline MetS components & & & & & & & & & \\
\hline & & (92.0) & & (91.1) & & (93.1) & & (92.0) & 0.227 \\
\hline Hyperglycemia & 1138 & (76.3) & & (73.7) & & $(74.6)$ & & (77.5) & 0.056 \\
\hline Hypertriglyceridemia & 835 & & & (55.4) & & $(56.9)$ & & (54.7) & 0.644 \\
\hline Low HDL-cholesterol & 657 & 44.0) & & (41.7) & & (41.1) & & (43.7) & 0.262 \\
\hline Abdominal obesity & 1341 & & & (96.2) & & (988.3) & & (99.7) & $<0.001$ \\
\hline
\end{tabular}

Abbreviations: BMI. Body Mass Index. PA. Physical activity. MedDiet Q. 17-item Mediterranean Diet Questionnaire HDL-cholesterol. High density lipoprotein cholesterol. § Desired body weight loss $=[$ (current body weight - ideal body weight $)$ /current body weight $] \times 100$. Due to the closeness of the cutting-percentiles, cut-offs were made considering a $5 \%$ of increase in desired body weight: Q1: $<10 \%$ desired body weight loss; Q2: 10-15\% desired body weight loss; Q3: 15-20\% desired body weight loss; Q4: $\geq 20 \%$ desired body weight loss. $†$ Measured in MET (Metabolic equivalent of task) min/week. || Other marital status were single and religious. † Living alone regardless of marital status. Difference in means between groups were tested by one-way ANOVA and Bonferroni's post-hoc when normally distributed or Kruskal-Wallis test when otherwise. Differences in prevalence's across groups were examined using $\chi^{2}$. Different letters indicate statistically significant differences between groups (a-f) according to Bonferroni's post-hoc analysis. 
Table 3. Adherence to the Mediterranean Diet 17-items according to the percentage of desired weight loss (DWL).

\begin{tabular}{|c|c|c|c|c|c|}
\hline & Q1 § $(n=1492)$ & $\mathrm{Q} 2 \S(n=1804)$ & $\mathrm{Q} 3 \S(n=1470)$ & $\mathrm{Q} 4 \S(n=1589)$ & \\
\hline MedDiet 17-items & $n(\%)$ & $n(\%)$ & $n(\%)$ & $n(\%)$ & $P$ \\
\hline 1: EVOO for cooking & $1152(77.2)$ & $1454(80.6)$ & $1151(78.3)$ & $1262(79.4)$ & 0.100 \\
\hline 2: Vegetables & $609(40.8)$ & $631(35.0)$ & $526(35.8)$ & $546(34.4)$ & 0.001 \\
\hline 3: Fruits & $758(50.8)$ & $829(46.0)$ & $675(45.9)$ & $698(43.9)$ & 0.001 \\
\hline 4: Red and processed meat & $772(51.7)$ & $856(47.5)$ & $654(44.5)$ & $745(46.9)$ & 0.001 \\
\hline 5: Butter, margarine, cream. & $1209(81.0)$ & $1460(80.9)$ & $1161(79.0)$ & $1246(78.4)$ & 0.149 \\
\hline 6: Sugar sweetened beverages & $1155(77.4)$ & $1354(75.1)$ & $1081(73.5)$ & $1162(73.1)$ & 0.029 \\
\hline 7: Legumes & $297(19.9)$ & $341(18.9)$ & $262(17.8)$ & $306(19.3)$ & 0.532 \\
\hline 8: Fish and seafood & $690(46.2)$ & $875(48.5)$ & $684(46.5)$ & $714(44.9)$ & 0.215 \\
\hline 9: Sweets and pastries & $908(60.9)$ & $1079(59.8)$ & $871(59.3)$ & $905(57.0)$ & 0.151 \\
\hline 10: Nuts & $650(43.6)$ & $814(45.1)$ & $550(37.4)$ & $545(34.3)$ & $<0.001$ \\
\hline 11: Preference white over red meat & $1114(74.7)$ & $1325(73.4)$ & $1092(74.3)$ & $1177(74.1)$ & 0.879 \\
\hline 12: Sofrito & $855(57.3)$ & $1036(57.4)$ & $826(56.2)$ & $885(55.7)$ & 0.701 \\
\hline 13: Adding sugar to beverages & $940(63.0)$ & $1104(61.2)$ & $945(64.3)$ & $1080(68.0)$ & 0.001 \\
\hline 14: White bread & $688(46.1)$ & $776(43.0)$ & $679(46.2)$ & $725(45.6)$ & 0.198 \\
\hline 15: Whole grains & $418(28.0)$ & $481(26.7)$ & $416(28.3)$ & $412(25.9)$ & 0.398 \\
\hline 16: Refined cereals & $486(32.6)$ & $534(29.6)$ & $449(30.5)$ & $473(29.8)$ & 0.250 \\
\hline 17: Wine & $342(22.9)$ & $463(25.7)$ & $329(22.4)$ & $317(19.9)$ & 0.001 \\
\hline MedDiet Adherence & & & & & 0.007 \\
\hline Low adherence $(0-7)$ & $487(32.6)$ & $655(36.3)$ & $550(37.4)$ & $600(37.8)$ & \\
\hline Moderate adherence (8-10) & $621(41.6)$ & 719 (39.9) & $591(40.2)$ & $662(41.7)$ & \\
\hline High adherence (11-17) & $384(25.7)$ & $430(23.8)$ & $329(22.4)$ & $327(20.6)$ & \\
\hline
\end{tabular}
of increase in desired body weight: Q1: $<10 \%$ desired body weight loss; Q2: 10-15\% desired body weight loss; Q3: 15-20\% desired body weight loss; Q4: $\geq 20 \%$ desired body weight loss. Differences in prevalence's across groups were examined using $\chi^{2}$. 
Table 4. Association between the adherence to the Mediterranean Diet 17-items (dependent variables) and the percentage of desired weight loss (independent variables) (DWL).

\begin{tabular}{|c|c|c|c|c|c|c|}
\hline & & $\begin{array}{c}\text { Q1 § } \\
(n=1492)\end{array}$ & $\begin{array}{c}\text { Q2 } \\
(n=1804)\end{array}$ & $\begin{array}{c}\text { Q3 } \S \\
(n=1470)\end{array}$ & $\begin{array}{c}\mathrm{Q} 4 \S \\
(n=1589)\end{array}$ & \\
\hline MedDiet 17-items & & OR $(95 \% \mathrm{CI})$ & OR $(95 \% \mathrm{CI})$ & OR $(95 \% \mathrm{CI})$ & OR $(95 \% \mathrm{CI})$ & $P$ \\
\hline \multirow{3}{*}{ 1: EVOO for cooking } & Crude OR & 1.00 (ref.) & $1.23(1.04-1.45)$ & $1.06(0.90-1.27)$ & $1.14(0.96-1.35)$ & 0.100 \\
\hline & OR adjusted 1 & 1.00 (ref.) & $1.26(1.06-1.50)$ & $1.13(0.93-1.36)$ & $1.30(1.05-1.61)$ & 0.030 \\
\hline & OR adjusted 2 & 1.00 (ref.) & $1.24(1.04-1.48)$ & $1.11(0.91-1.34)$ & $1.28(1.04-1.59)$ & 0.045 \\
\hline \multirow{3}{*}{ 2: Vegetables } & Crude OR & 1.00 (ref.) & $0.78(0.68-0.90)$ & $0.81(0.70-0.94)$ & $0.76(0.66-0.88)$ & 0.001 \\
\hline & OR adjusted 1 & 1.00 (ref.) & $0.78(0.68-0.91)$ & $0.84(0.71-0.99)$ & $0.80(0.67-0.96)$ & 0.012 \\
\hline & OR adjusted 2 & 1.00 (ref.) & $0.77(0.67-0.90)$ & $0.84(0.71-0.99)$ & $0.80(0.66-0.96)$ & 0.008 \\
\hline \multirow{3}{*}{ 3: Fruits } & Crude OR & 1.00 (ref.) & $0.82(0.72-0.94)$ & $0.82(0.71-0.95)$ & $0.76(0.66-0.87)$ & 0.001 \\
\hline & OR adjusted 1 & 1.00 (ref.) & $0.86(0.74-0.99)$ & $0.86(0.73-1.01)$ & $0.80(0.67-0.96)$ & 0.077 \\
\hline & OR adjusted 2 & 1.00 (ref.) & $0.87(0.75-1.00)$ & $0.87(0.74-1.03)$ & $0.81(0.68-0.97)$ & 0.133 \\
\hline \multirow{3}{*}{$\begin{array}{l}\text { 4: Red and processed } \\
\text { meat }\end{array}$} & Crude OR & 1.00 (ref.) & $0.84(0.73-0.97)$ & $0.75(0.65-0.86)$ & $0.82(0.71-0.95)$ & 0.001 \\
\hline & OR adjusted 1 & 1.00 (ref.) & $0.85(0.74-0.98)$ & $0.78(0.66-0.92)$ & $0.85(0.71-1.02)$ & 0.022 \\
\hline & OR adjusted 2 & 1.00 (ref.) & $0.85(0.73-0.98)$ & $0.78(0.66-0.92)$ & $0.85(0.71-1.02)$ & 0.024 \\
\hline \multirow{3}{*}{$\begin{array}{l}\text { 5: Butter, margarine, } \\
\text { cream }\end{array}$} & Crude OR & 1.00 (ref.) & $0.99(0.83-1.18)$ & $0.88(0.73-1.05)$ & $0.85(0.71-1.01)$ & 0.149 \\
\hline & OR adjusted 1 & 1.00 (ref.) & $1.02(0.85-1.22)$ & $0.91(0.75-1.11)$ & $0.90(0.72-1.12)$ & 0.535 \\
\hline & OR adjusted 2 & 1.00 (ref.) & $1.02(0.85-1.23)$ & $0.92(0.75-1.12)$ & $0.91(0.73-1.13)$ & 0.559 \\
\hline \multirow{3}{*}{$\begin{array}{l}\text { 6: Sugar sweetened } \\
\text { beverages }\end{array}$} & Crude OR & 1.00 (ref.) & $0.88(0.75-1.03)$ & $0.81(0.69-0.96)$ & $0.79(0.67-0.94)$ & 0.029 \\
\hline & OR adjusted 1 & 1.00 (ref.) & $0.89(0.75-1.05)$ & $0.82(0.68-0.98)$ & $0.81(0.66-0.99)$ & 0.149 \\
\hline & OR adjusted 2 & 1.00 (ref.) & $0.89(0.75-1.05)$ & $0.82(0.68-0.98)$ & $0.81(0.66-0.99)$ & 0.147 \\
\hline \multirow{3}{*}{ 7: Legumes } & Crude OR & 1.00 (ref.) & 0.94(0.79-1.12) & $0.87(0.73-1.05)$ & $0.96(0.80-1.15)$ & 0.533 \\
\hline & OR adjusted 1 & 1.00 (ref.) & $0.97(0.81-1.16)$ & $0.94(0.77-1.15)$ & $1.06(0.85-1.33)$ & 0.637 \\
\hline & OR adjusted 2 & 1.00 (ref.) & $0.98(0.81-1.17)$ & $0.95(0.77-1.16)$ & $1.06(0.85-1.33)$ & 0.678 \\
\hline \multirow{3}{*}{ 8: Fish and seafood } & Crude OR & 1.00 (ref.) & $1.09(0.95-1.26)$ & $1.01(0.88-1.17)$ & $0.95(0.82-1.09)$ & 0.215 \\
\hline & OR adjusted 1 & 1.00 (ref.) & $1.13(0.98-1.30)$ & $1.05(0.89-1.23)$ & $1.00(0.84-1.20)$ & 0.284 \\
\hline & OR adjusted 2 & 1.00 (ref.) & $1.13(0.98-1.31)$ & $1.05(0.90-1.24)$ & $1.01(0.84-1.20)$ & 0.272 \\
\hline \multirow{3}{*}{$\begin{array}{l}\text { 9: Sweets and } \\
\text { pastries }\end{array}$} & Crude OR & 1.00 (ref.) & $0.96(0.83-1.10)$ & $0.94(0.81-1.08)$ & $0.85(0.74-0.98)$ & 0.151 \\
\hline & OR adjusted 1 & 1.00 (ref.) & $0.98(0.85-1.14)$ & $1.00(0.84-1.18)$ & $0.90(0.75-1.08)$ & 0.598 \\
\hline & OR adjusted 2 & 1.00 (ref.) & $0.98(0.85-1.14)$ & $1.00(0.85-1.18)$ & $0.90(0.75-1.08)$ & 0.596 \\
\hline \multirow{3}{*}{ 10: Nuts } & Crude OR & 1.00( & $1.07(0.93-1.22)$ & $0.77(0.67-0.90)$ & $0.68(0.58-0.78)$ & $<0.001$ \\
\hline & OR adjusted 1 & 1.00 (ref.) & $1.14(0.98-1.32)$ & $0.88(0.75-1.03)$ & $0.85(0.71-1.02)$ & 0.001 \\
\hline & OR adjusted 2 & 1.00 (ref.) & $1.14(0.98-1.31)$ & $0.88(0.75-1.03)$ & $0.85(0.71-1.02)$ & 0.001 \\
\hline \multirow{3}{*}{$\begin{array}{l}\text { 11: Preference for } \\
\text { white over red meat }\end{array}$} & Crude OR & 1.00 (ref.) & $0.94(0.80-1.10)$ & $0.98(0.83-1.16)$ & $0.97(0.82-1.14)$ & 0.879 \\
\hline & OR adjusted 1 & 1.00 (ref.) & $0.95(0.81-1.12)$ & $1.03(0.85-1.23)$ & $1.01(0.82-1.24)$ & 0.802 \\
\hline & OR adjusted 2 & 1.00 (ref.) & $0.96(0.81-1.13)$ & $1.04(0.87-1.25)$ & $1.02(0.83-1.25)$ & 0.785 \\
\hline \multirow{3}{*}{ 12: Sofrito } & Crude OR & 1.00 (ref.) & $1.01(0.87-1.15)$ & $0.96(0.83-1.11)$ & $0.94(0.81-1.08)$ & 0.701 \\
\hline & OR adjusted 1 & 1.00 (ref.) & $1.03(0.89-1.19)$ & $1.02(0.87-1.20)$ & $1.06(0.88-1.26)$ & 0.940 \\
\hline & OR adjusted 2 & 1.00 (ref.) & $1.04(0.90-1.20)$ & $1.03(0.88-1.21)$ & $1.06(0.89-1.26)$ & 0.934 \\
\hline \multirow{3}{*}{$\begin{array}{l}\text { 13: Adding sugar to } \\
\text { beverages }\end{array}$} & Crude OR & 1.00 (ref.) & $0.93(0.80-1.07)$ & $1.06(0.91-1.23)$ & $1.25(1.07-1.45)$ & 0.001 \\
\hline & OR adjusted 1 & 1.00 (ref.) & $0.85(0.73-0.99)$ & $0.93(0.79-1.10)$ & $1.00(0.83-1.20)$ & 0.093 \\
\hline & OR adjusted 2 & 1.00 (ref.) & $0.86(0.74-0.99)$ & $0.95(0.80-1.12)$ & $1.01(0.84-1.22)$ & 0.112 \\
\hline \multirow{3}{*}{ 14: White bread } & Crude OR & 1.00 (ref.) & $0.88(0.77-1.01)$ & $1.00(0.87-1.16)$ & $0.98(0.85-1.13)$ & 0.198 \\
\hline & OR adjusted 1 & 1.00 (ref.) & $0.84(0.72-0.97)$ & $0.97(0.82-1.14)$ & $0.85(0.71-1.02)$ & 0.048 \\
\hline & OR adjusted 2 & 1.00 (ref.) & $0.83(0.72-0.97)$ & $0.97(0.82-1.14)$ & $0.85(0.70-1.02)$ & 0.037 \\
\hline \multirow{3}{*}{ 15: Whole grains } & Crude OR & 1.00 (ref.) & $0.93(0.80-1.09)$ & $1.01(0.86-1.19)$ & $0.90(0.77-1.05)$ & 0.398 \\
\hline & OR adjusted 1 & 1.00 (ref.) & $0.91(0.78-1.07)$ & $0.99(0.83-1.19)$ & $0.85(0.70-1.04)$ & 0.246 \\
\hline & OR adjusted 2 & 1.00 (ref.) & $0.91(0.77-1.07)$ & $1.00(0.83-1.19)$ & $0.85(0.70-1.04)$ & 0.215 \\
\hline \multirow{3}{*}{ 16: Refined cereals } & Crude OR & 1.00 (ref.) & $0.87(0.75-1.01)$ & $0.91(0.78-1.06)$ & $0.88(0.75-1.02)$ & 0.251 \\
\hline & OR adjusted 1 & 1.00 (ref.) & $0.85(0.73-0.99)$ & $0.88(0.74-1.04)$ & $0.79(0.65-0.96)$ & 0.089 \\
\hline & OR adjusted 2 & 1.00 (ref.) & $0.84(0.72-0.98)$ & $0.87(0.73-1.04)$ & $0.78(0.65-0.95)$ & 0.066 \\
\hline \multirow{3}{*}{ 17: Wine } & Crude OR & 1.00 (ref.) & $1.16(0.99-1.36)$ & $0.97(0.82-1.15)$ & $0.84(0.71-1.00)$ & 0.001 \\
\hline & OR adjusted 1 & 1.00 (ref.) & $1.27(1.07-1.51)$ & $1.11(0.91-1.35)$ & $1.11(0.89-1.38)$ & 0.045 \\
\hline & OR adjusted 2 & 1.00 (ref.) & $1.25(1.05-1.49)$ & $1.08(0.89-1.32)$ & $1.10(0.88-1.37)$ & 0.069 \\
\hline
\end{tabular}

Abbreviations: OR. Odds Ratio. OR adjusted 1: Odds Ratio adjusted by sociodemographic characteristics (Age, gender, BMI, physical activity, diet, education level, marital status and smoking habit). OR adjusted 2: Odds Ratio adjusted by sociodemographic characteristics (Age, gender, BMI, physical activity, diet, education level, marital status and smoking habit) and presence of metabolic syndrome components. $\S$ Desired body weight loss $=[$ (current body weight - ideal body weight)/current body weight] $\times 100$. Due to the closeness of the cutting-percentiles, cut-offs were made considering a $5 \%$ of increase in desired body weight: Q1: $<10 \%$ desired body weight loss; Q2: 10-15\% desired body weight loss; Q3: $15-20 \%$ desired body weight loss; Q4: $\geq 20 \%$ desired body weight loss. 
Some associations were modified due to adjustment by potential confounders. While OR for items regarding vegetables, red meat and nuts remained similar to crude OR (between 0.6-0.9 times lower for Q4 than Q1), fruits and sugary sweetened beverage items lost their statistical significance due to adjustment. OR for consuming white bread was 0.80-0.85 times lower for Q2 than for Q1, and, only in women also for Q4. On the other hand, men in Q4 had an OR 0.68 times lower for consuming less than 3 portions of refined cereals per week than those in Q1. Regarding the use of extra virgin olive oil for cooking, Q2 and Q4 had an OR 1.3 times higher, while for women alone OR for Q4 increased up to 1.6. The OR of drinking wine changed after adjustment only by sociodemographic factors, Q2 (10-15\% desired weight loss) has an OR of 1.27.

\section{Discussion}

In the present study, DWL was inversely associated with Mediterranean lifestyle (diet and physical activity) and directly associated with BMI and abdominal obesity. Previous studies reported that BMI was associated with a higher discrepancy between current body weight and subjective ideal weight [24]. Regardless of the exception of African American women, ideal weight tends to fall within the normal weight range $[42,43]$. This supports our hypothesis that higher DWL in people with overweight, especially when some comorbidities are present, might be motivated by a high current weight and a desire to improve health. Moreover, a recent study showed that in normal weight individuals, overestimation of weight status together with diagnosis of metabolic syndrome, increases weight loss efforts [44]. This health motivator might also be an explanation of the finding that, in women, percentage of former smokers increased as DWL increased.

In the present study, higher DWL were related to lower levels of physical activity, which was consistent with existing literature [24,45-50]. High weight perception has been associated with lower levels of physical activity in adults [51], however current results are controversial and no definite conclusion can be drawn in this regard [50]. Some hypothesis have been made to explain these relationships, such as negative evaluations to develop exercise in public [52,53], or that physical activity modified body perception and helped to maintain a satisfactory body image [54,55], and therefore lower DWL. Self-perception has been described as a motivator for senior women to start exercising [56]; nonetheless, exercise would help weight management and therefore decrease DWL.

Our findings show no relationships between energy intake and DWL, unlike existing literature, which has associated body image dissatisfaction to high energy intake [45]. A plausible explanation would point out that DWL might affect energy intake reporting; however, there is little and yet mixed evidence on the relation between energy intake underreporting and ideal weight. While for adults lower ideal than current weight has been associated with underreporting 339 kilocalories per day [57], in women aged 50-75 years old there were no associations with underreporting energy [58]. Therefore, it cannot be assumed that DWL is affecting energy intake reporting.

The available literature on the topic is consistent with our results regarding food consumption and DWL. On one hand, having a large body image has been associated with unhealthier dietary patterns, such as higher intakes of sweet drinks and refined foods. On the other hand, small body image has been associated to a healthy dietary pattern, rich in fruits and vegetables [59]. Body dissatisfaction caused by an excess of weight has also been associated with unhealthy eating habits, such as ultra-processed foods [60]. In this regard, the present study found that as DWL increased, so did sugar sweetened beverage consumption, especially in women, as well as avoidance to add sugar to beverages also increased, mainly in men. Considering DWL as a source of stress, chocolates, biscuits, cakes, sweets and palatable snacks were consumed more frequently under stress, as opposed to fish, meat, fruits and vegetables, which are the less consumed foods under stress [61]. Furthermore, low ideal BMI has been associated with weight management [16]. Lowering fat consumption is a technique that men are likely to apply to lose weight [62]. This could explain why nuts consumption was lower among those in the Q4. Moreover weight management has been associated with a higher consumption of fruits and vegetables, especially in women $[24,63,64]$. The low consumption of fruits and vegetables in Q4 could 
be related to low pursuit of their ideal weight. This theory is supported by existing literature, stating that compared with population aged under 40 years old, those over 60 settled for lower weight loss expectations [65] and therefore had a lower pursuit of weight control.

Although some research was unsure about the adequacy of the MedDiet as a long term weight loss method [66], more recent evidence has shown that the MedDiet is a valid strategy for long term weight management [67-69], and is, moreover, effective in reducing obesity adverse health consequences [3]. In the present study, DWL was inversely associated to Mediterranean lifestyle adherence. Those findings align with the existing literature on the topic, which has associated weight dissatisfaction with less healthy lifestyles, understood as healthy diet and exercise, contrary to weight satisfaction that related to healthier lifestyles $[24,45,70]$. Weight dissatisfaction was also related to greater intention to change lifestyle [24]. Moreover, identifying oneself as part of a socially stigmatized group also may promote less healthy dietary habits $[70,71]$ On the other hand, as suggested above, if bigger DWL in this population were primarily motivated by health pursuits, they might not be capable of spontaneously following a healthy lifestyle, which would improve general health.

The present population is living in a Mediterranean country, immersed in the Mediterranean culture and lifestyle; but at the same time, the current globalization is spreading the influence of the western eating style [72]. The MedDiet has been described as a dietary pattern characterized by a high intake of olive oil as the main source of culinary fat, and high intakes of vegetables, fruits, nuts, legumes and fish, at the expense of a lower intake of meat [13], while the western-style diet is a high-calorie pattern rich in refined wheat, meat, and sodas and a low intake of legumes, nuts, fish, fruits and vegetables [11,72]. Bearing in mind the present results regarding compliance with MedDiet items and DWL, it could be suggested that DWL might have a higher impact on those dietary items or food groups for which the Western and Mediterranean patterns differ the most, such as fruits, vegetables, nuts, red meat and sodas. On the other hand, those aspects of the MedDiet assumed to be more cultural, such as "sofrito" making, legumes, or fish consumption were the items that remained more stable among groups of DWL, or, as happened for olive oil, even improved adherence in some groups, also supporting the health pursuit theory. Therefore, the dietary patterns of participants reporting higher DWL might be more influenced by the western eating style, altogether with lower dietary quality and physical activity, than subjects with lower DWL.

The group with higher DWL was the youngest. Aging has been related to lower weight loss expectations [65] and to healthier diet [73,74]. In our study, analysis was adjusted by age, hence, we can assume that the associations found between diet and DWL are not affected by age.

\section{Strengths and Limitations of the Study}

The present study contributes to the very limited evidence tackling the relationship between dietary lifestyle and body image in populations aged over 55 years old. Other strengths of the present study include its large sample size and the use of two different tools to assess dietary intake: the FFQ and the 17-item MedDiet. On the top of that, results would be very easily transferred into clinical practice, as groups were defined within $5 \%$ of desired weight loss. This classification makes it easier to transfer results to everyday clinical practice.

Nonetheless, the present study has some limitations. The main limitation would be that causal inferences cannot be established, as it has a cross-sectional design. Secondly, it has been described that, when starting a weight loss program, ideal weight is lower than real weight and related to maximum weight loss previously achieved $[75,76]$. Therefore, not taking into consideration realistic weight losses is the second limitation of the present study. In addition, body image is a multidimensional construct that is hard to simplify [77]. The authors are aware that there are other validated methods to assess body image and dissatisfaction $[78,79]$ that were not used in the present research. In the present work we tried to simplify the assessment of body image through surrogate parameters that are easily obtained in clinical practice. This was done to allow transference of present findings to clinical practice. Thirdly, FFQ, even after being validated, might overestimate intake of certain food groups. 
For all that, participants reporting extreme energy intakes were excluded, and the 17-item MedDiet was used to contrast, to avoid information bias [80]. Moreover, due to the lack of data collection, the influence of economic status could not be evaluated as a confounder. Lastly, all participants in the present study were over 55 years and about to start a healthier lifestyle as part of the PREDIMED-Plus trial, and had high cardiovascular risk, which is a limitation to make results extensible to the general adult population.

\section{Conclusions}

Following Mediterranean lifestyle is beneficial for general health, especially for those who are already at risk due to an excess of weight. The present study showed that in a population with an excess of weight aged over 55 years, DWL inversely correlated to Mediterranean lifestyle, by adherence to MedDiet and levels of physical activity. As DWL increased, food intake shifted to low dietary quality, through an unhealthy dietary pattern rich in processed foods and sugary sweetened beverages, and low intake of fruits and vegetables. The most rooted aspects of the MedDiet remain stable regardless of the DWL. Moreover, physical activity decreased as DWL increased. DWL could be a tool for health care professionals to detect whether a person is at risk due to an unhealthy lifestyle. As it has been related to lower physical activity and specific diet components, those should be specially addressed in further detail by health care professionals. More research is needed in this regard, to validate and further define the potential tool.

The present study increases the little evidence regarding physical self-perception in older adults. Further research on DWL and lifestyle ought to be conducted. To be able to establish causality, longitudinal design is advised. It is necessary to explore if the less healthy lifestyle is influencing DWL or if it is the other way around, to be able to design more effective weight management strategies.

Supplementary Materials: The following are available online at http:/www.mdpi.com/2072-6643/12/7/2114/s1, Table S1: Sociodemographic characteristics according to percentage of desired weight loss (DWL) in MEN, Table S2: Sociodemographic characteristics according to percentage of desired weight loss (DWL) in WOMEN, Table S3: Adherence to the Mediterranean Diet 17-items according to the percentage of desired weight loss (DWL) in MEN, Table S4. Adherence to the Mediterranean Diet 17-items according to the percentage of desired weight loss (DWL) in WOMEN.

Author Contributions: C.B., M.d.M.B. and J.A.T. conducted the statistical analyses and drafted the article. C.B., M.d.M.B. and J.A.T. made substantial contributions to the conception and design of the work. All authors contributed substantially in the acquisition of data or analysis and interpretation of data. All authors revised the article critically for important intellectual content. All authors have read and agreed to the published version of the manuscript.

Funding: The PREDIMED-Plus trial was supported by the official funding agency for biomedical research of the Spanish government, ISCIII, through the Fondo de Investigación para la Salud (FIS), which is co-funded by the European Regional Development Fund (five coordinated FIS projects led by J.S.-S. and J.Vidal, including the following projects: PI13/00673, PI13/00492, PI13/00272, PI13/01123, PI13/00462, PI13/00233, PI13/02184, PI13/00728, PI13/01090, PI13/01056, PI14/01722, PI14/00636, PI14/00618, PI14/00696, PI14/01206, PI14/01919, PI14/00853, PI14/01374, PI14/00972, PI14/00728, PI14/01471, PI16/00473, PI16/00662, PI16/01873, PI16/01094, PI16/00501, PI16/00533, PI16/00381, PI16/00366, PI16/01522, PI16/01120, PI17/00764, PI17/01183, PI17/00855, PI17/01347, PI17/00525, PI17/01827, PI17/00532, PI17/00215, PI17/01441, PI17/00508, PI17/01732, PI17/00926, PI19/00957, PI19/00386, PI19/00309, PI19/01032, PI19/00576, PI19/00017, PI19/01226, PI19/00781, PI19/01560, and PI19/01332, the Especial Action Project entitled: Implementación y evaluación de una intervención intensiva sobre la actividad física Cohorte PREDIMED-Plus grant to J.S.-S., the European Research Council (Advanced Research Grant 2013-2018, 340918) to Miguel Ángel Martínez-González, the Recercaixa Grant to J.S.-S. (2013ACUP00194), Grants from the Consejería de Salud de la Junta de Andalucía (PI0458/2013, PS0358/2016, and PI0137/2018), a Grant from the Generalitat Valenciana (PROMETEO/2017/017), a SEMERGEN Grant, EU-COST Action CA16112, a Grant of support to research groups no. 35/2011 from the Balearic Islands Government, Grants from Balearic Islands Health Research Institute (IDISBA), funds from the European Regional Development Fund (CIBEROBN CB06/03 and CB12/03) and from the European Commission (EAT2BENICE_H2020_SFS2016). M. Rosa Bernal-López was supported by "Miguel Servet Type I" program (CP15/00028) from the ISCIII-Madrid (Spain), cofinanced by the European Regional Development Fund. Jordi Salas-Salvadó is partially supported by ICREA under the ICREA Academia programme. Cristina Bouzas received a Fernando Tarongí Bauzà PhD Grant. I.M Gimenez-Alba received a grant FPU from the Ministry of Science, Innovation and Univesities (reference FPU 18/01703). The funding sponsors had no role in the design of the study, in the collection, analyses, or interpretation of the data; in the writing of the manuscript, and in the decision to publish the results. 
Acknowledgments: The authors especially thank the PREDIMED-Plus participants for their enthusiastic collaboration, the PREDIMED-Plus personnel for outstanding support, and the personnel of all associated primary care centres for their exceptional effort. CIBEROBN, CIBERESP and CIBERDEM are initiatives of Instituto de Salud Carlos III, Spain. We thank the PREDIMED-Plus Biobank Network, part of the National Biobank Platform of Instituto de Salud Carlos III for storing and managing biological samples.

Conflicts of Interest: J.S.-S. reports serving on the board of and receiving grant support through his institution from the International Nut and Dried Fruit Council, and Eroski Foundation. Reports serving in the Executive Committee of the Instituto Danone Spain and on the Scientific Committee of the Danone International Institute. He has received research support from PatrimonioComunalOlivarero, Spain; and Borges S.A., Spain. Reports receiving consulting fees or travel expenses from Danone; Eroski Foundation, Instituto Danone-Spain, and Abbot Laboratories.

Availability of Data and Materials: There are restrictions on the availability of data for the PREDIMED-Plus trial, due to the signed consent agreements around data sharing, which only allow access to external researchers for studies following the project purposes. Requestors wishing to access the PREDIMED-Plus trial data used in this study can make a request to the PREDIMED-Plus trial Steering Committee chair: jordi.salas@urv.cat. The request will then be passed to members of the PREDIMED-Plus Steering Committee for deliberation.

\section{References}

1. Ju, S.Y.; Lee, J.Y.; Kim, D.H. Association of metabolic syndrome and its components with all-cause and cardiovascular mortality in the elderly: A meta-analysis of prospective cohort studies. Medicine 2017, 96, e8491. [CrossRef]

2. Zhao, Y.; Li, Z.; Yang, T.; Wang, M.; Xi, X. Is body mass index associated with outcomes of mechanically ventilated adult patients in intensive critical units? A systematic review and meta-analysis. PLoS ONE 2018, 13, e0198669. [CrossRef]

3. Zhang, X.; Xie, X.; Dou, Q.; Liu, C.; Zhang, W.; Yang, Y.; Deng, R.; Cheng, A.S. Association of sarcopenic obesity with the risk of all-cause mortality among adults over a broad range of different settings: A updated meta-analysis. BMC Geriatr. 2019, 19, 183. [CrossRef]

4. Ulian, M.D.; Aburad, L.; da Silva Oliveira, M.S.; Poppe, A.C.M.; Sabatini, F.; Perez, I.; Gualano, B.; Benatti, F.B.; Pinto, A.J.; Roble, O.J.; et al. Effects of health at every size ${ }^{\circledR}$ interventions on health-related outcomes of people with overweight and obesity: A systematic review. Obes. Rev. 2018, 19, 1659-1666. [CrossRef]

5. Warkentin, L.M.; Das, D.; Majumdar, S.R.; Johnson, J.A.; Padwal, R.S. The effect of weight loss on health-related quality of life: Systematic review and meta-analysis of randomized trials. Obes. Rev. 2014, 15, 169-182. [CrossRef] [PubMed]

6. Chang, A.R.; Grams, M.E.; Ballew, S.H.; Bilo, H.; Correa, A.; Evans, M.; Gutierrez, O.M.; Hosseinpanah, F.; Iseki, K.; Kenealy, T.; et al. Adiposity and risk of decline in glomerular filtration rate: Meta-analysis of individual participant data in a global consortium. BMJ 2019, 364, k5301. [CrossRef] [PubMed]

7. Prospective Studies Collaboration and Asia Pacific Cohort Studies Collaboration. Sex-specific relevance of diabetes to occlusive vascular and other mortality: A collaborative meta-analysis of individual data from 980 793 adults from 68 prospective studies. Lancet Diabetes Endocrinol. 2018, 6, 538-546. [CrossRef]

8. Kwon, Y.; Kim, H.J.; Park, S.; Park, Y.G.; Cho, K.H. Body Mass Index-Related Mortality in Patients with Type 2 Diabetes and Heterogeneity in Obesity Paradox Studies: A Dose-Response Meta-Analysis. PLoS ONE 2017, 12, e0168247. [CrossRef]

9. Hui, L. Assessment of the role of ageing and non-ageing factors in death from non-communicable diseases based on a cumulative frequency model. Sci. Rep. 2017, 7, 8159. [CrossRef] [PubMed]

10. Estruch, R.; Ros, E.; Salas-Salvadó, J.; Covas, M.I.; Corella, D.; Arós, F.; Gómez-Gracia, E.; Ruiz-Gutiérrez, V.; Fiol, M.; Lapetra, J.; et al. Primary prevention of cardiovascular disease with a Mediterranean diet. Supplemented with Extra-Virgin Olive Oil or Nuts. N. Engl. J. Med. 2018, 378, e34. [CrossRef]

11. D'Alessandro, A.; De Pergola, G. The Mediterranean Diet: Its definition and evaluation of a priori dietary indexes in primary cardiovascular prevention. Int. J. Food Sci. Nutr. 2018, 69, 647-659. [CrossRef] [PubMed]

12. Villani, A.; Sultana, J.; Doecke, J.; Mantzioris, E. Differences in the interpretation of a modernized Mediterranean diet prescribed in intervention studies for the management of type 2 diabetes: How closely does this align with a traditional Mediterranean diet? Eur. J. Nutr. 2019, 58, 1369-1380. [CrossRef] [PubMed] 
13. Davis, C.; Bryan, J.; Hodgson, J.; Murphy, K. Definition of the Mediterranean diet: A literature review. Nutrients 2015, 7, 9139-9153. [CrossRef] [PubMed]

14. Bach-Faig, A.; Berry, E.M.; Lairon, D.; Reguant, J.; Trichopoulou, A.; Dernini, S.; Medina, F.X.; Battino, M.; Belahsen, R.; Miranda, G.; et al. Mediterranean diet pyramid today. Science and cultural updates. Public Health Nutr. 2011, 14, 2274-2284. [CrossRef]

15. Diolintzi, A.; Panagiotakos, D.B.; Sidossis, L.S. From Mediterranean diet to Mediterranean lifestyle: A narrative review. Public Health Nutr. 2019, 22, 2703-2713. [CrossRef]

16. Bouzas, C.; Bibiloni, M.M.; Tur, J.A. Relationship between body image and body weight control in overweight 255-year-old adults: A systematic review. Int. J. Environ. Res. Public Health 2019, 16, 1622. [CrossRef]

17. Tory Higgins, E. Beyond pleasure and pain. Am. Psychol. 1997, 52, 1280-1300. [CrossRef]

18. Vance, K.; Howe, W.; Dellavalle, R.P. Social internet sites as a source of public health information. Dermatol. Clin. 2009, 27, 133-136. [CrossRef]

19. Caruso, G.; Fortuna, F. Mediterranean diet Patterns in the Italian Population: A functional data analysis of Google Trends. In Decisions and Trends in Social Systems, Innovative and Integrated Approaches of Care Services; Springer: Berlin, Germany, 2020.

20. Jung, F.; Spahlholz, J.; Hilbert, A.; Riedel-Heller, S.G.; Luck-Sikorski, C. Impact of Weight-Related Discrimination, Body Dissatisfaction and Self-Stigma on the Desire to Weigh Less. Obes. Facts 2017, 10, 139-151. [CrossRef]

21. National Eating Disorders Collaboration. Body Image. Available online: https://www.nedc.com.au/eatingdisorders/eating-disorders-explained/body-image/ (accessed on 13 January 2020).

22. Pearson, A.N.; Heffner, M.; Follette, V.M. Chapter 2: Acceptance and commitment therapy: An introduction. In Acceptance \& Commitment Therapy for Body Image Dissatisfaction: A Practitioner's Guide to Using Mindfulness, Acceptance \& Values-based Behavior Change Strategies; Pearson, A.N., Heffner, M., Follette, V.M., Eds.; New Harbinger Publications: Oakland, CA, USA, 2010; pp. 17-36.

23. Maynard, L.M.; Serdula, M.K.; Galuska, D.A.; Gillespie, C.; Mokdad, A.H. Secular trends in desired weight of adults. Int. J. Obes. 2006, 30, 1375-1381. [CrossRef]

24. Kuk, J.L.; Ardern, C.I.; Church, T.S.; Hebert, J.R.; Sui, X.; Blair, S.N. Ideal weight and weight satisfaction: Association with health practices. Am. J. Epidemiol. 2009, 170, 456-463. [CrossRef] [PubMed]

25. Martínez-González, M.A.; Buil-Cosiales, P.; Corella, D.; Bulló, M.; Fitó, M.; Vioque, J.; Romaguera, D.; Martínez, J.A.; Wärnberg, J.; López-Miranda, J.; et al. Cohort profile: Design and methods of the PREDIMED-Plus randomized trial. Int. J. Epidemiol. 2019, 48, 387-388. [CrossRef] [PubMed]

26. Alberti, K.G.M.M.; Eckel, R.H.; Grundy, S.M.; Zimmet, P.Z.; Cleeman, J.I.; Donato, K.A.; Fruchart, J.C.; James, W.P.T.; Loria, C.M.; Smith, S.C., Jr. Harmonizing the metabolic syndrome: A joint interim statement of the international diabetes federation task force on epidemiology and prevention; National heart, lung, and blood institute; American heart association; World heart federation; International atherosclerosis society; And international association for the study of obesity. Circulation 2009, 120, 1640-1645.

27. Fernández-Ballart, J.D.; Piñol, J.L.; Zazpe, I.; Corella, D.; Carrasco, P.; Toledo, E.; Perez-Bauer, M.; Martínez-González, M.Á.; Salas-Salvadó, J.; Martín-Moreno, J.M. Relative validity of a semi-quantitative food-frequency questionnaire in an elderly Mediterranean population of Spain. Br. J. Nutr. 2010, 103, 1808-1816. [CrossRef]

28. Martin-Moreno, J.M.; Boyle, P.; Gorgojo, L.; Maisonneuve, P.; Fernandez-Rodriguez, J.C.; Salvini, S.; Willett, W.C. Development and validation of a food frequency questionnaire in Spain. Int. J. Epidemiol. 1993, 22, 512-519. [CrossRef]

29. De la Fuente-Arrillaga, C.; Ruiz, Z.V.; Bes-Rastrollo, M.; Sampson, L.; Martinez-González, M.A. Reproducibility of an FFQ validated in Spain. Public Health Nutr. 2010, 13, 1364-1372. [CrossRef]

30. Moreiras, O.; Cabrera, L.; Cuadrado, C. Tablas de Composición de Alimentos (Spanish Food Composition Tables), 17th ed.; Pirámide: Madrid, Spain, 2015.

31. Mataix-Verdú, J.; García-Diz, L.; Mañas-Almendros, M.; Martinez de Victoria, E.; Llopis-González, J. Tablas de Composición de Alimentos, 5th ed.; Universidad de Granada: Granada, Spain, 2013.

32. Sánchez-Tainta, A.; Zazpe, I.; Bes-Rastrollo, M.; Salas-Salvadó, J.; Bullo, M.; Sorlí, J.V.; Corella, D.; Covas, M.I.; Arós, F.; Gutierrez-Bedmar, M.; et al. Nutritional adequacy according to carbohydrates and fat quality. Eur. J. Nutr. 2016, 55, 93-106. [CrossRef] 
33. Álvarez-Álvarez, I.; Martínez-González, M.Á.; Sánchez-Tainta, A.; Corella, D.; Díaz-López, A.; Fitó, M.; Vioque, J.; Romaguera, D.; Martínez, J.A.; Wärnberg, J.; et al. Adherence to an Energy-restricted Mediterranean Diet Score and Prevalence of Cardiovascular Risk Factors in the PREDIMED-Plus: A Cross-sectional Study. Rev. Esp. Cardiol. 2019, 72, 925-934. [CrossRef] [PubMed]

34. Galilea-Zabalza, I.; Buil-Cosiales, P.; Salas-Salvadó, J.; Toledo, E.; Ortega-Azorín, C.; Díez-Espino, J.; Vázquez-Ruiz, Z.; Zomeño, M.D.; Vioque, J.; Martínez, J.A.; et al. Mediterranean diet and quality of life: Baseline cross-sectional analysis of the PREDIMED-PLUS trial. PLoS ONE 2018, 13, e0198974. [CrossRef] [PubMed]

35. American Psychiatric Association. Diagnostic and Statistical Manual of Mental Disorders, 5th ed.; American Psychiatric Association: Washington, DC, USA, 2013.

36. Brestoff, J.R.; Perry, I.J.; Van Den Broeck, J. Challenging the role of social norms regarding body weight as an explanation for weight, height, and BMI misreporting biases: Development and application of a new approach to examining misreporting and misclassification bias in surveys. BMC Public Health 2011, 11, 331. [CrossRef]

37. Bibiloni, M.D.M.; Coll, J.L.; Pich, J.; Pons, A.; Tur, J.A. Body image satisfaction and weight concerns among a Mediterranean adult population. BMC Public Health 2017, 17, 39. [CrossRef] [PubMed]

38. Molina, L.; Sarmiento, M.; Peñafiel, J.; Donaire, D.; Garcia-Aymerich, J.; Gomez, M.; Ble, M.; Ruiz, S.; Frances, A.; Schröder, H.; et al. Validation of the Regicor Short Physical Activity Questionnaire for the Adult Population. PLoS ONE 2017, 12, e0168148. [CrossRef] [PubMed]

39. Elosua, R.; Garcia, M.; Aguilar, A.; Molina, L.; Covas, M.I.; Marrugat, J. Validation of the Minnesota Leisure Time Physical Activity Questionnaire In Spanish Women. Investigators of the MARATDON Group. Med. Sci. Sports Exerc. 2000, 32, 1431-1437. [CrossRef] [PubMed]

40. Elosua, R.; Marrugat, J.; Molina, L.; Pons, S.; Pujol, E. Validation of the Minnesota Leisure Time Physical Activity Questionnaire in Spanish men. The MARATHOM Investigators. Am. J. Epidemiol. 1994, 139, 1197-1209. [CrossRef] [PubMed]

41. Martínez-González, M.A.; López-Fontana, C.; Varo, J.J.; Sánchez-Villegas, A.; Martinez, J.A. Validation of the Spanish version of the physical activity questionnaire used in the Nurses' Health Study and the Health Professionals' Follow-up Study. Public Health Nutr. 2005, 8, 920-927. [CrossRef]

42. Wardle, J.; Johnson, F. Weight and dieting: Examining levels of weight concern in British adults. Int. J. Obes. Relat. Metab. Disord. 2002, 26, 1144-1149. [CrossRef]

43. Sánchez-Johnsen, L.A.P.; Fitzgibbon, M.L.; Martinovich, Z.; Stolley, M.R.; Dyer, A.R.; Van Horn, L. Ethnic differences in correlates of obesity between Latin-American and black women. Obes. Res. 2004, 12, 652-660.

44. Lee, K. Estimation of weight status and weight-loss efforts in Korean adults with non-obesity considering metabolic syndrome. Eat Weight Disord. 2019, 24, 135-142. [CrossRef]

45. Ginsberg, R.L.; Tinker, L.; Liu, J.; Gray, J.; Sangi-Haghpeykar, H.; Manson, J.A.E.; Margolis, K.L. Prevalence and correlates of body image dissatisfaction in postmenopausal women. Women Health 2016, 56, $23-47$. [CrossRef]

46. Coelho, C.G.; Giatti, L.; Molina, M.D.C.B.; Nunes, M.A.A.; Barreto, S.M. Body image and nutritional status are associated with physical activity in men and women: The ELSA-Brasil study. Int. J. Environ. Res. Public Health 2015, 12, 6179-6196. [CrossRef]

47. Marshall, C.; Lengyel, C.; Utioh, A. Body dissatisfaction among middle-aged and older women. Can. J. Diet. Pract. Res. 2012, 73, e241-e247. [CrossRef] [PubMed]

48. Atlantis, E.; Barnes, E.H.; Ball, K. Weight status and perception barriers to healthy physical activity and diet behavior. Int. J. Obes. 2008, 32, 343-352. [CrossRef] [PubMed]

49. Horm, J.; Anderson, K. Who in America is Trying to Lose Weight? Ann. Intern. Med. 1993, 119, 672-676. [CrossRef] [PubMed]

50. Haynes, A.; Kersbergen, I.; Sutin, A.; Daly, M.; Robinson, E. A systematic review of the relationship between weight status perceptions and weight loss attempts, strategies, behaviours and outcomes. Obes. Rev. 2018, 19, 347-363. [CrossRef] [PubMed]

51. Duncan, D.T.; Wolin, K.Y.; Scharoun-Lee, M.; Ding, E.L.; Warner, E.T.; Bennett, G.G. Does perception equal reality? Weight misperception in relation to weight-related attitudes and behaviors among overweight and obese US adults. Int. J. Behav. Nutr. Phys. Act. 2011, 8, 20. [CrossRef] [PubMed] 
52. Vartanian, L.R.; Shaprow, J.G. Effects of weight stigma on exercise motivation and behavior: A preliminary investigation among college-aged females. J. Health Psychol. 2008, 13, 131-138. [CrossRef] [PubMed]

53. Ball, K.; Crawford, D.; Owen, N. Too fat to exercise? Obesity as a barrier to physical activity. Aust. N. Z. J. Public Health 2000, 24, 331-333. [CrossRef] [PubMed]

54. Murillo, R.; Ali, S.A.; Carmack, C.; Doss, D. Activity and weight misperception among overweight and obese US adults. Am. J. Health Behav. 2016, 40, 12-20. [CrossRef]

55. Condello, G.; Capranica, L.; Stager, J.; Forte, R.; Falbo, S.; Di Baldassarre, A.; Segura-Garcia, C.; Pesce, C. Physical activity and health perception in aging: Do body mass and satisfaction matter? A three-path mediated link. PLoS ONE 2016, 11, e0160805. [CrossRef]

56. Wang, W.C.; Worsley, A.; Cunningham, E.G. Social ideological influences on food consumption, physical activity and BMI. Appetite 2009, 53, 288-296. [CrossRef]

57. Novotny, J.A.; Rumpler, W.V.; Riddick, H.; Hebert, J.R.; Rhodes, D.; Judd, J.T.; Baer, D.J.; McDowell, M.; Briefel, R. Personality characteristics as predictors of underreporting of energy intake on 24-hour dietary recall interviews. J. Am. Diet. Assoc. 2003, 103, 1146-1151. [CrossRef]

58. Mossavar-Rahmani, Y.; Tinker, L.F.; Huang, Y.; Neuhouser, M.L.; McCann, S.E.; Seguin, R.A.; Vitolins, M.Z.; Curb, J.D.; Prentice, R.L. Factors relating to eating style, social desirability, body image and eating meals at home increase the precision of calibration equations correcting self-report measures of diet using recovery biomarkers: Findings from the Women's Health Initiative. Nutr. J. 2013, 12, 63. [CrossRef] [PubMed]

59. Romieu, I.; Escamilla-Núñez, M.C.; Sánchez-Zamorano, L.M.; Lopez-Ridaura, R.; Torres-Mejía, G.; Yunes, E.M.; Lajous, M.; Rivera-Dommarco, J.A.; Lazcano-Ponce, E. The association between body shape silhouette and dietary pattern among Mexican women. Public Health Nutr. 2012, 15, 116-125. [CrossRef]

60. Oliveira, N.; Coelho GM de, O.; Cabral, M.C.; Bezerra, F.F.; Faerstein, E.; Canella, D.S. Association of body image (dis)satisfaction and perception with food consumption according to the NOVA classification: Pró-Saúde Study. Appetite 2019, 144, 104464. [CrossRef] [PubMed]

61. Oliver, G.; Wardle, J. Perceived effects of stress on food choice. Physiol. Behav. 1999, 66, 511-515. [CrossRef]

62. Hubert, H.B.; Snider, J.; Winkleby, M.A. Health status, health behaviors, and acculturation factors associated with overweight and obesity in Latinos from a community and agricultural labor camp survey. Prev. Med. 2005, 40, 642-651. [CrossRef]

63. Rodríguez-Rodríguez, E.; Aparicio, A.; López-Sobaler, A.M.; Ortega, R.M. Body weight perception and dieting behaviour in Spanish population. Nutr. Hosp. 2009, 24, 580-587.

64. Tsai, S.A.; Lv, N.; Xiao, L.; Ma, J. Gender Differences in Weight-Related Attitudes and Behaviors among Overweight and Obese Adults in the United States. Am. J. Mens Health 2016, 10, 389-398. [CrossRef]

65. Evans, E.H.; Boothroyd, L.G.; Muscariello, E.; Stephan, B.C.M.; Nasti, G.; Colantuoni, A.; Siervo, M. Lower weight loss expectations and healthier eating attitudes in older overweight and obese women attempting weight loss. Clin. Obes. 2015, 5, 136-144. [CrossRef]

66. Malik, V.S.; Hu, F.B. Popular weight-loss diets: From evidence to practice. Nat. Clin. Pract. Cardiovasc. Med. 2007, 4, 34-41. [CrossRef]

67. Serra-Majem, L. Efficacy of diets in weight loss regimens: Is the Mediterranean diet appropiate? Pol. Arch. Med. Wewn. 2008, 118, 691-693. [CrossRef] [PubMed]

68. Esposito, K.; Kastorini, C.M.; Panagiotakos, D.B.; Giugliano, D. Mediterranean diet and weight loss: Meta-analysis of randomized controlled trials. Metab. Syndr. Relat. Disord. 2011, 9, 1-12. [CrossRef] [PubMed]

69. Mancini, J.G.; Filion, K.B.; Atallah, R.; Eisenberg, M.J. Systematic Review of the Mediterranean Diet for Long-Term Weight Loss. Am. J. Med. 2016, 129, 407-415.e4. [CrossRef] [PubMed]

70. Vartanian, L.R.; Porter, A.M. Weight stigma and eating behavior: A review of the literature. Appetite 2016, 102, 3-14. [CrossRef]

71. Major, B.; Hunger, J.M.; Bunyan, D.P.; Miller, C.T. The ironic effects of weight stigma. J. Exp. Soc. Psychol. 2014, 51, 74-80. [CrossRef]

72. Rizzello, F.; Spisni, E.; Giovanardi, E.; Imbesi, V.; Salice, M.; Alvisi, P.; Valerii, M.C.; Gionchetti, P. Implications of the westernized diet in the onset and progression of IBD. Nutrients 2019, 11, 1033. [CrossRef]

73. Lahmann, P.H.; Kumanyika, S.K. Attitudes about health and nutrition are more indicative of dietary quality in 50- to 75-year-old women than weight and appearance concerns. J. Am. Diet. Assoc. 1999, 99, 475-478. [CrossRef] 
74. Uccula, A.; Nuvoli, G. Body perception and meal type across age and gender on a Mediterranean island (Sardinia). Psychol. Health Med. 2017, 22, 1210-1216. [CrossRef]

75. Dalle Grave, R.; Calugi, S.; Magri, F.; Cuzzolaro, M.; Dall'Aglio, E.; Lucchin, L.; Melchionda, N.; Marchesini, G.; QUOVADIS Study Group. Weight loss expectations in obese patients seeking treatment at medical centers. Obes. Res. 2004, 12, 2005-2012. [CrossRef]

76. Cachelin, F.M.; Striegel-Moore, R.H.; Elder, K.A. Realistic weight perception and body size assessment in a racially diverse community sample of dieters. Obes. Res. 1998, 6, 62-68. [CrossRef]

77. Banfield, S.S.; McCabe, M.P. An evaluation of the construct of body image. Adolescence 2002, 37, $373-393$. [PubMed]

78. Thompson, J.K.; Tantleff-Dunn, S. Assessment of body image disturbance in obesity. Obes. Res. 1998, 6, 375-377. [CrossRef] [PubMed]

79. Pull, C.B.; Aguayo, G.A. Assessment of body-image perception and attitudes in obesity. Curr. Opin. Psychiatry 2011, 24, 41-48. [CrossRef] [PubMed]

80. Tripepi, G.; Jager, K.J.; Dekker, F.W.; Zoccali, C. Selection bias and information bias in clinical research. Nephron. Clin. Pract. 2010, 115, 94-99. [CrossRef] [PubMed]

(C) 2020 by the authors. Licensee MDPI, Basel, Switzerland. This article is an open access article distributed under the terms and conditions of the Creative Commons Attribution (CC BY) license (http://creativecommons.org/licenses/by/4.0/). 